\title{
Anxiety Disorders: From Bench to Bedside and Beyond
}

\author{
Dr. Jonathan Starke* \\ Prof. Naomi Fineberg \\ Prof. Dan Stein
}

*Corresponding author: Dr Jonathan Starke, Department of Psychiatry and Mental Health, University of Cape town, South Africa, joestarke@gmail.com, +27 734617297

\section{Abstract}

The anxiety disorders are common, associated with high comorbidity and cause considerable disability. Despite effective treatment options, they are frequently misdiagnosed, and management is often sub-optimal. With the recent publication of the DSM 5 and the imminent release of the ICD 11, there have been important debates about how best to catagorise and conceptualise these disorders. In addition, their underlying neurobiology is being explored at multiple levels from systems neuroscience to molecular biology and genetics - an endeavor that is delivering key insights with relevance to clinical practice. Furthermore, several international anxiety disorder treatment guidelines have recently been published, and large systematic reviews and meta-analyses have addressed important questions around clinical management. All of this indicates the need for an update on advances in this rapidly developing field, and this chapter therefore provides an overview of the epidemiology and classification, cognitive-affective neuroscience, and clinical management of the anxiety disorders.

\section{Keywords}

Anxiety disorders; DSM 5; neuroscience; fear circuit; amygdala; neuropeptides; treatment guidelines; $d$-cycloserine; pregabalin; mindfulness

\section{Introduction}

Anxiety disorders are the commonest group of mental illnesses globally, and associated with a significant disease burden, which is compounded by under-diagnosis and incorrect or inadequate treatment $(1,2)$. Though anxiety disorders can have a chronic or relapsing and remitting course, many treatment options are now available, and there can often be considerable improvement.

The best outcomes for patients are achieved through a sound understanding of 3 interlinking issues: the clinical features and epidemiology of anxiety disorders, so that the right diagnosis is considered and made; the neurobiological factors underlying the clinical presentation, which inform both research and treatment strategies; and the efficacy and effectiveness of the psychotherapeutic and psychopharmacological options, which allows for evidence-based and individualized care. The preceding 
Accepted Manuscript.

Book chapter (https://doi.org/10.1007/978-3-319-70554-5 2) published in "Advances in Psychiatry" (https://doi.org/10.1007/978-3-319-70554-5), Springer Nature, 07/07/2018.

volumes of the Advances in Psychiatry series have not focused on anxiety disorders directly, meaning this chapter is an important opportunity to update readers on a range of advances in the field. The literature is vast, however, so instead of trying to be exhaustive, this review focuses on key developments that have particular relevance for conceptualization, improving diagnosis and achieving the best possible treatment outcomes.

We begin by discussing the epidemiology, and recent developments in the diagnosis and classification of the conditions, including reference to the Diagnostic and Statistical Manual 5 (DSM 5) and upcoming International Classification of disease version 11 (ICD 11), and consideration of how the Research Domain Criteria (RDoC) framework may inform our conceptualization and management of these disorders. Subsequently, we give an overview of the neurobiological characteristics of the anxiety disorders extending from functional neuroimaging to genetics. Finally, we discuss treatment options and guidelines based on recent psychotherapeutic and pharmacological research, with a specific focus on generalized anxiety disorder, panic disorder and agoraphobia, specific phobia, and social anxiety disorder.

\section{Section 1: Understanding a worried world....}

\section{Epidemiology and disease burden of anxiety disorders}

Though it has long been recognized that anxiety disorders are common, robust evidence clarifying the full extent of the problem globally has been lacking, due to both inadequate measurement tools, as well as mental health being given a lower priority than other health issues in epidemiological research (3). This lack of evidence is an important problem that has contributed to under detection and poorly informed mental health policy (3). In recent years, large-scale epidemiological studies are beginning to address this gap, and are providing important insights.

The World Mental Health Survey (WMHS) is an ongoing community survey using structured interviews aimed at providing information about the prevalence, distribution, burden, and unmet need for treatment of common mental disorders, including the anxiety disorders (1). Anxiety disorders are consistently the commonest group of mental disorders in the general population globally, with conservative lifetime prevalence estimates for any anxiety disorder averaging $16 \%$, and as high as $31 \%(1,4)$. This is in comparison to the next most common disorders, namely mood disorders, with an average lifetime prevalence of $12 \%$ (1).

In terms of individual anxiety disorders, specific phobia is the most prevalent (7-9\% 12-month prevalence), followed by social anxiety disorder (2-7\% 12-month prevalence), and then general anxiety disorder (approx. 3\% 12-month prevalence) (1, 5). A more recent WMHS has also highlighted the high lifetime prevalence of panic attacks (13.2\%), though the lifetime prevalence for panic disorder was only $1.7 \%$, which is equivalent to the prevalence of agoraphobia $(1,6,7)$. As a group, the anxiety disorders are more common in women (4), and on average have their onset in the late teens or early $20 \mathrm{~s}(8)$. It is also recognized that while appropriate treatment can modify the long-term trajectory of these disorders, they naturally have a chronic or 
Accepted Manuscript.

Book chapter (https://doi.org/10.1007/978-3-319-70554-5 2) published in "Advances in Psychiatry" (https://doi.org/10.1007/978-3-319-70554-5), Springer Nature, 07/07/2018.

relapsing and remitting course $(7,9)$, and are also commonly underdiagnosed and undertreated $(2,10)$.

A further important clinical and epidemiological factor is the high comorbidity associated with anxiety disorders. This includes having more than one anxiety disorder, as well as comorbid mood, substance use and physical disorders $(8,11)$. In those with at least one anxiety disorder diagnosis (i.e. a clinical sample); an estimated $10 \%$ will have a second anxiety disorder, $29 \%$ will have an anxiety disorder and a depressive disorder, and 31\% will have 2 anxiety disorders and at least 1 depressive disorder (11). This is in comparison to general population estimates which suggest a lifetime prevalence of $5 \%$ of an anxiety disorder and comorbid mood disorder (including bipolar disorder and major depression) and approximately $3 \%$ for an anxiety disorder and a comorbid substance use disorder (8). In the majority of cases, the anxiety disorder presents first, which is important from a diagnostic and management perspective (8).

The presence of comorbid disorders adds considerably to the disease burden associated with anxiety disorders, specifically in terms of chronicity, more severe symptoms, more social disability and greater utilisation of health services (11). Apart from the impact of comorbid conditions, the disease burden associated with anxiety disorders directly is an important focus of current research, most notably through the WMHS and Global Burden of Disease Studies $(1,12,13)$. In part due to their early onset and chronicity, anxiety disorders are particularly associated with problematic longterm consequences, including increased risk for physical illness, reduced educational attainment, marital instability, lower occupational and financial achievement, and substantially increased utilization of healthcare resources (1). In a global analysis of mental disorders, anxiety disorders were second only to major depressive disorder in terms of disease burden (12).

Central to understanding the consequences of anxiety disorders, and mental illness in general, is realising that their impact is under-represented if only mortality rates are considered. So, even though anxiety disorders do predict increased mortality $(14,15)$, and even when they have contributed directly to death, for example in the case of suicide, the cause of death will usually be recorded as the proximate cause (such as hanging, poisoning etc.), and the associated mental illness may not be highlighted (13). To counter this potential misrepresentation of the importance of mental illness, epidemiologists now calculate additional measures of impact, specifically Disability Adjusted Life Years (DALYs), Years of Life Lost (YLL)s and Years Lived with Disability (YLDs) (13). When seen from this perspective, the high burden of anxiety disorders becomes clear, as they account for 3.5\% of the global disease burden due to disability (measured in YLDs), second only to major depressive disorders amongst mental disorders, and the sixth leading global cause of disability overall in both high, middle and low income countries $(12,13)$.

The factors described so far emphasise the need for coordinated efforts to better manage anxiety disorders. This can best be achieved by screening in at risk groups, making the diagnosis based on standardized criteria, and initiating evidencebased treatment, for both the anxiety disorder and any comorbid conditions. In line with this, clear agreement on the clinical features of each diagnosis is essential, as it 
Accepted Manuscript.

Book chapter (https://doi.org/10.1007/978-3-319-70554-5 2) published in "Advances in Psychiatry" (https://doi.org/10.1007/978-3-319-70554-5), Springer Nature, 07/07/2018.

allows for standardized approaches to research, which can then contribute to clinical decision making and policy development.

\section{Name changes, re-organisation and thinking outside (and about) the box}

Psychiatric diagnosis has been criticized as lacking in diagnostic certainty and scientific rigor (16). Though this view can be disputed as premature, given the complexity of the brain, and the relative newness of neuroscience as a discipline, disease classification systems such as the DSM and ICD represent coordinated attempts to address this issue. By standardizing diagnostic criteria, they provide a reliable means for determining "caseness", which is currently foundational for anxiety disorder research, as it provides a common language through which to communicate about and investigate their causes and consequences $(3,4,17)$.

The development and eventual release of the DSM 5 in 2013, after intensive and prolonged international collaboration, allowed for an update of psychiatric diagnoses and disorder groupings, including for the anxiety disorders. There have been important criticisms of the final document, and the debate about these has the potential to strengthen the field and future versions $(16,18,19)$. Changes relating to the anxiety disorders include new clustering of disorders, as well as new diagnostic criteria (7). Most notably when compared to DSM IV, obsessive-compulsive disorder and post-traumatic stress disorder (PTSD) are now grouped separately from the anxiety disorders in the "Obsessive Compulsive and Related Disorders" and "Trauma and Stressor-related disorders" chapters respectively. There is divided opinion on the justification for these changes, particularly in relation to PTSD $(20,21)$. A potential advantage, however, will be divergent research pathways for these disorders, which may clarify the underlying neurobiology and allow progress towards more targeted treatment (22). Further re-organisation involving anxiety disorders includes the placement of separation anxiety disorder and selective mutism within the anxiety disorder section, rather than in Disorders Usually First Diagnosed in Infancy, Childhood, or Adolescence. For separation anxiety disorder, this change was made because a significant number of people only experience separation anxiety after the age of 18 yrs., while selective mutism was moved because of the high likelihood of significant anxiety in children who are selectively mute $(7,23)$.

Apart from this re-grouping, the DSM 5 also includes a number of other changes, including to names and diagnostic criteria. Panic disorder and agoraphobia are now regarded as separate conditions, even though it remains clear that there is considerable comorbidity, and there is now a panic attack specifier that can be applied to any mental condition (7). For agoraphobia, specific phobia and social anxiety disorder, the person no longer needs to recognize that their anxiety is excessive or unreasonable, instead it is now up to the clinician to determine that symptoms are out of proportion to reality (7). For social anxiety disorder, the term social phobia falls away, and symptoms must now have been present for more than 6 months across all age groups, while a "performance only" specifier has been added.

Though many may have hoped that the DSM 5 would be a paradigm shift in how mental illness is conceptualized, the changes to the anxiety disorders are an example of how it has been a more iterative process, with a paradigm shift not yet 
Accepted Manuscript.

Book chapter (https://doi.org/10.1007/978-3-319-70554-5 2) published in "Advances in Psychiatry" (https://doi.org/10.1007/978-3-319-70554-5), Springer Nature, 07/07/2018.

possible (24-26). Still, these changes may represent a worthwhile refinement of thinking about anxiety and anxiety disorders (22).

The imminent release of the ICD 11 will provide further fuel to the debate about disease classification, especially relating to mental illness. Overall, efforts have been made to harmonize the ICD 11 and DSM 5, so as to allow for cross-talk for those using both systems, and to allow meaningful integration for statistical purposes. The ICD 11 aims to emphasize clinical utility, which has been identified as a possible weakness of the DSM $5(16,18,27)$, which itself is an attempt at validity - though both systems clearly strive for both aspects. Even though the changes expected in the ICD 11 for the anxiety disorders are broadly in line with those in the $\operatorname{DSM} 5(27,28)$, it remains important that clinicians and researchers are rigorous in reviewing both classification systems to the extent to which they can inform practice, and to facilitate testing of both with the goal of further development and refinement through research (29).

While categorical systems such as the DSM 5 and ICD 11 are currently indispensable in clinical and research psychiatry (3), the limitations of these approaches indicate the need for new ways of conceptualizing mental illness and making diagnoses $(16,18,19)$. The Research Domain Criteria (RDoC) project initiated by the National Institutes of Mental Health in the USA is a leading example $(18,30)$. The goal of the RDoC is to move towards "precision medicine for psychiatry" (18) by developing a robust biological basis for psychiatric diagnosis and treatment though the rigorous exploration of 5 research domains, namely: negative valence systems including fear and anxiety, positive valence systems, cognitive systems, social processes, and regulatory and arousal systems $(17,30)$. Each of these domains is further extrapolated into subconstructs, and research is ongoing on the genetic, molecular, cellular, physiological, behavioural and systems levels (30).

The RDoC project, while clearly a valuable long-term initiative which builds on many years of neuroscience research, is still at a very early stage. So, while there has been some discussion of whether the RDoC may represent the beginnings of a paradigm shift for the anxiety disorders (31), it has yet to have a major impact on clinical management. Nevertheless, it may usefully serve as a stimulus for clinicians and researchers to remain flexible and inquisitive, to seek to not only think outside the "box" of diagnostic categories and conceptualizations, but also to think about the box itself, and whether or not there is, or even should be, a box at all. Though the final outcomes of the RDoC initiative are some way off, there is already a large body of research on the neurobiological underpinnings of anxiety disorders, which we will now review.

\section{Section 2: The anxious brain - what's going on in there?}

In the past 2 decades, neuroscience research, both in humans and animal models, has expanded $(17,32,33)$, with ongoing development and refinement of methodologies at both the "macro" level (especially structural and functional neuroimaging) and "micro" level (especially genetics and molecular biology). The result has been steady headway in deepening our understanding of the neurobiology 
Accepted Manuscript.

Book chapter (https://doi.org/10.1007/978-3-319-70554-5 2) published in "Advances in Psychiatry" (https://doi.org/10.1007/978-3-319-70554-5), Springer Nature, 07/07/2018.

of psychiatric illness $(34,35)$. We present here an overview of the cognitive-affective neuroscience of anxiety, in order to informs diagnosis and treatment.

\section{Anxiety circuits and systems}

The signs and symptoms of anxiety disorders are diverse, including cognitive features such as prominent rumination and attentional difficulties; emotional aspects, including fear and dysphoria; and physical changes and experiences such as breathlessness or tachycardia, (7). This indicates that multiple brain regions and systems are implicated in both the vulnerability to anxiety and in its acute manifestation, and the neuroscience literature confirms that anxiety is a "whole brain" problem involving cortical, limbic and brainstem structures and networks (10, $33,36,37)$.

A key circuit thought to underlie experiences of anxiety and the anxiety disorders themselves is the "fear circuit" $(10,36)$, which is involved in fear conditioning (the development of fear in response to a stimulus), fear extinction (the diminution and disappearance of fear in response to a previously fearful stimulus), and the fear response itself (the physiological and overt manifestations of fear). This circuit was initially delineated in animal work, mostly in rodents, but because of the preservation of fear-related systems through evolution, an analogous system exists in humans, the understanding of which guides clinical applications $(10,38-40)$.

Critical brain structures initially implicated in fear conditioning and fear extinction in humans include the amygdala, hippocampus, and prefrontal cortex (PFC) $(10,36)$. Other work suggests a role for the insula cortex and anterior cingulate cortex (ACC) $(17,41)$. These regions interact to process fearful stimuli received through afferent connections from multiple other brain structures, and then coordinate the fear response via efferent connections especially with the hypothalamus and autonomic nervous system control centres in the brainstem, which are involved principally in the expression of fear $(10,17,39)$. The amygdala and hippocampus play central roles in the acquisition of conditioned fear, while the prefrontal cortex has a top-down modulatory function over amygdala activity levels, which regulates GABAergic connections between the amygdala, and brainstem, thus regulating fear expression $(36,38)$. In addition, it is postulated that while the amygdala is responsible for the "positive" features of fear (such as hyperarousal), the hippocampus may govern the "negative" symptoms (such as avoidance), a separation that may reflect different evolutionary origins, with the amygdala's role reflecting an implicit process that likely evolved earlier, while the hippocampus mediates a more explicit process relying on memories of past fearful stimuli (10). Relying on the same circuitry, fear extinction (achieved for example through graduated exposure) involves upregulation of PFC inputs and thus reduced output from the amygdala $(36,40)$.

The system described above evolved in response to the realities of the evolutionary environment, and when triggered in response to appropriately threatening stimuli remains adaptive, and as a result has been preserved across evolution $(10,39)$. In the anxiety disorders however, the structures and circuitry malfunction, with the result that problematic symptoms arise that can be usefully conceptualized as different types of "false alarms" in response to the pressures of modern life (10). It remains difficult to determine if the abnormalities in the fear 
Accepted Manuscript.

Book chapter (https://doi.org/10.1007/978-3-319-70554-5 2) published in "Advances in Psychiatry" (https://doi.org/10.1007/978-3-319-70554-5), Springer Nature, 07/07/2018.

circuitry detected in anxiety disorder research are causal, or the consequence of some other as yet unrecognized factor, but understanding the changes remains valuable in explaining the symptoms of anxiety, as well as the mechanism of effect of established and novel treatment approaches.

In individuals with high trait anxiety and those with anxiety disorders, there may be dynamic imbalance between the amygdala and the PFC, with amygdala hyperresponsivity, and insufficient recruitment of prefrontal input, resulting in alterations in attentional, associative and interpretive processes in response to threatening or potentially threatening stimuli $(36,38,40)$. Hyperactivity of the insula may compound this (17), with the overall result that those with anxiety disorders have a "threat-related processing bias" or "negativity bias" $(17,36)$, with selective attention to threatening stimuli and resultant poor performance, and distressing symptoms. In research paradigms exploring this, the threatening stimulus need not have reached conscious awareness for it to have an impact, i.e. even fleeting stimuli can be significant $(36,38)$. In addition, those with anxiety disorders are also more likely to misinterpret neutral or ambiguous stimuli as threatening $(10,36,42)$. Combined this enhancement/ exaggeration of threat evaluation mechanisms in anxiety disorders results in more frequent perceptions of threat and the associated activation of the fear response, with an increased likelihood of fear conditioning, and a reduced likelihood of fear extinction (40). This potential runaway cycle may be involved in both the etiology and maintenance of anxiety and anxiety disorders (36).

These changes appear to be relevant to the anxiety disorders as a group (40), with research in individual disorders confirming this and highlighting more disorderspecific aspects. PTSD in particular, while no longer grouped with the anxiety disorders in the DSM 5, nevertheless is mediated by the fear circuitry mechanisms (40). Panic disorder, agoraphobia and specific phobia, which revolve around fear conditioning experiences and impaired fear extinction, also appear to stem from dysregulation of this system, particularly relating to the balance between amygdala and PFC activity $(10,17,40)$. In social anxiety disorder (SAD) and generalized anxiety disorder (GAD), the insula component of the fear circuitry is also implicated (38), and ACC hypoactivity and insufficient connectivity between the ACC and amygdala during processing of threat stimuli also appears significant in the manifestation and maintenance of anxiety (17). In addition, the over-interpretation of social cues which may contribute towards anxiety in those with SAD, may be more specifically linked with dorsolateral PFC (DLPFC) and dorsal ACC hypoactivity (10), while the chronic worry and rumination characteristic of GAD (which is in contrast to the more focused experiences of fear and anxiety present in the phobic disorders and panic disorder), may stem from additional dysfunction in a "cognitive control circuit" including the DLPFC, ACC, dorsal parietal cortex and precentral gyrus, representing a form of "cognitive overdrive" (17).

Despite these important advances, which bring clarity to the neurobiological processes underlying the anxiety disorders, there is much still to be determined. Particularly, the circuitry underlying specific symptoms of anxiety, and further details of the unique features present in the different disorders, as well as which features are transdiagnostic, needs elaboration. As mentioned in the discussion of classification, it is likely that the current anxiety disorders do not map neatly onto discrete neurobiological processes (18). Further work on the cognitive-affective neuroscience 
Accepted Manuscript.

Book chapter (https://doi.org/10.1007/978-3-319-70554-5 2) published in "Advances in Psychiatry" (https://doi.org/10.1007/978-3-319-70554-5), Springer Nature, 07/07/2018.

of anxiety has the potential to move the field towards a biological basis for understanding symptoms, and for assisting with the determination of diagnosis, classification and treatment. The RDoC project is an example of a coordinated effort towards this end, and the negative valence system domain is particularly likely to provide valuable insight for understanding anxiety (30). Broad-based, longitudinal research projects exploring anxiety symptoms by combining neuroimaging and symptom measures in diverse subjects, and relating this to behaviour and functioning, are currently underway (17).

\section{Anxious genes and molecules}

Intensive research is also focused on what is happening at the "micro" level within the anxious brain. This includes both animal and human studies focusing on endocrine pathways (especially the hypothalamic-pituitary-adrenal axis), neurotransmitter systems (including monoamine pathways, as well as glutamatergic and GABAergic functioning); an ever increasing number of neuropeptides; and at a fundamental level, the role of genetic factors in the vulnerability towards anxiety disorders - all of which align with the goals of the RDoC project $(30,32,35,38,43$, 44). This important research agenda compliments the larger systems-level work already described, with the potential to deepen the understanding of the neurobiology of anxiety, and assist in developing possible diagnostic biomarkers, clarify the effects of established treatments, and lay the foundation for identifying novel treatment targets and therapeutic agents $(44,45)$. Though the available literature in this area is extensive, and interested readers should refer to more in depth reviews $(34,35,38)$, what follows is a summary of key points to inform the later discussion of treatment.

\section{Hypothalamic-pituitary-adrenal axis (HPA-axis)}

The HPA axis is central to the bodies' response to stress, and HPA axis dysfunction may be present in a subset of anxiety disorders (38). The neuropeptide corticotrophin releasing factor (CRF), is a key regulatory factor for the HPA axis, and has a neuromodulatory effect with specific relevance to anxiety, including via anxietyrelated targets outside the axis itself, such as the amygdala $(35,38,45)$. Brain areas involved in anxiety show high expression of CRF receptors, especially the frontal cortex, hippocampus and amygdala, and CRF receptor antagonists are an intense focus of research as possible therapeutic agents, with some encouraging early findings $(38,45)$. While CRF over-expression has been most clearly linked to anxiety in rodents (45), behavioural inhibition in children - a risk factor for SAD and panic disorder - is associated with CRF gene polymorphisms, though CRF-related findings in specific anxiety disorders are inconsistent, and it is not a uniform abnormality (38). In addition, in panic disorder there may be reduced sensitivity to CRF (specifically a reduced HPA axis response to its release), which may in part explain the intense anxiety symptoms characteristic of the disorder (38).

Finally, besides CRF itself, there are other endogenous ligands of the CRF receptor that may be relevant, including the neuropeptides urocontin 1 and 2, which appear to be involved in adaptive stress recovery processes, and dysfunction within this system may increase vulnerability to stress, including development of anxiety 
Accepted Manuscript.

Book chapter (https://doi.org/10.1007/978-3-319-70554-5 2) published in "Advances in Psychiatry" (https://doi.org/10.1007/978-3-319-70554-5), Springer Nature, 07/07/2018.

disorders (45). This is an example of the extensive interconnections that exist between the various molecular subsystems relevant to anxiety.

\section{Monoamine systems with a focus on serotonin}

The role of monoamines (including serotonin, noradrenaline and to a lesser extent dopamine) in the etiology of anxiety disorders has been recognized for some time $(10,38)$, and rests in part on the fact that pharmacological agents targeting monoamine pathways are effective anxiolytics (46), as well as the extensive monoaminergic projections present throughout the fear circuitry (10). The relevant research has been reviewed at length $(35,47,48)$. An important recent stream is the sustained focus of interest on the serotonergic receptors and the serotonin transporter, as they are believed to underlie the benefits of the selective serotonin reuptake inhibitors (SSRIs) - currently the first-line medications for anxiety disorders $(2,46)$. This line of enquiry unites genetics and molecular biology and highlights the value of translational approaches across animal and human research, with the potential to clarify the mechanism of effects of SSRIs and other anxiolytics targeting this system (46). There is already clear evidence of a role for the $5 \mathrm{HT} 1 \mathrm{~A}$ receptor in modulating anxiety in animal models, and while initial attempts at developing effective receptor agonists as therapeutic agents in humans were unsuccessful, it remains an active interest area $(46,47)$. Additional work in humans highlights the distribution of the $5 \mathrm{HT} 1 \mathrm{~A}$ receptor in key components of the fear circuitry (prefrontal cortex and hippocampus), and the association of $5 \mathrm{HT} 1 \mathrm{~A}$ receptor gene polymorphism with amygdala reactivity, indicating a likely effect on anxiety expression (46).

Alongside the $5 \mathrm{HT} 1 \mathrm{~A}$ receptor, the $5 \mathrm{HT} 2$ group of receptors (most notably $5 \mathrm{HT} 2 \mathrm{C}$ ) are implicated in the etiology of anxiety, and may be a mechanism for the effectiveness of anxiolytics $(35,46)$. In animal models, $5 \mathrm{HT} 2$ antagonists augment the effect of SSRIs, though human trials have not yet demonstrated any benefit (46). The existing agent agomelatine, which apart from its melatonergic effects, is also a $5 \mathrm{HT} 2 \mathrm{C}$ receptor antagonist, has been shown to be an anxiolytic in those with GAD, and this may be due to its influence on this receptor (49). In addition, there appears to be a functional interaction between $5 \mathrm{HT} 2$ receptors and $\mathrm{CRF}$, that may have a role in modulating fear extinction, and the $5 \mathrm{HT} 2 \mathrm{~A}$ receptor has co-activity with $\mathrm{GABA}_{\mathrm{A}}$ receptors at certain sites (46) - inter-relationships which exemplify the complexity of the molecular basis of anxiety.

The serotonin transporter $(5 \mathrm{HTT})$ is probably the most widely studied component of the serotonergic system, in large part because it is a key mechanism for the effects of the SSRIs (46). 5HTT gene variants have been identified as a risk factor for anxiety traits and disorders, and possibly a reduced ability to tolerate or adapt to stress $(36,46)$. This may be due to an effect of these gene variants on amygdala activity, a change specifically relevant to SAD (10). As a further example of the interaction between the various molecular sub-systems involved in anxiety, there is some indication that 5HTT and the functioning of the neuropeptide oxytocin may be intertwined (46). In animal genetic models, knock-in and knockout approaches have confirmed a role for $5 \mathrm{HTT}$ in anxiety, which may be the early beginnings of genetically targeted treatments for anxiety disorders (46). 
Accepted Manuscript.

Book chapter (https://doi.org/10.1007/978-3-319-70554-5 2) published in "Advances in Psychiatry" (https://doi.org/10.1007/978-3-319-70554-5), Springer Nature, 07/07/2018.

This has been only a brief glimpse of serotonergic research, but what is obvious, is that, despite its central place in anxiety research, this system doesn't operate in isolation (48). Apart from the connections already described, the serotonergic system also has important reciprocal relationships with the opioid and GABA systems $(46,50)$, and the fact that a significant number of those with anxiety disorders do not respond to serotonergic treatments is an important reminder to keep other molecular sub-systems in mind too (45).

\section{Glutamate and GABA}

Apart from the monoamines, the classical neurotransmitters glutamate and gamma-aminobutyric acid (GABA) also have important and intertwined roles in anxiety $(44,51)$. Glutamate is the main excitatory neurotransmitter, while GABA is the main inhibitory neurotransmitter, with the dynamic balance between them essential to effective brain functioning. GABA inhibitory interneurons are a core component of the fear circuitry within the amygdala (36), with a prominent role in the expression of anxiety, including as the intermediaries for the top-down control exerted by the PFC in the down-regulation of the amygdala, a process that is dysfunctional in anxiety disorders $(36,40)$. Psychotherapeutic interventions involving exposure are thought to upregulate PFC input to the amygdala, and achieve their benefit in part by modulating these GABAergic neurons (36).

The central importance of GABAergic neurons in anxiety is confirmed by the fact that they are the molecular targets of the benzodiazepines, which are effective anxiolytics $(46,52)$. There is also some evidence of a role for GABA-related genes in increasing vulnerability to anxiety disorders, though this is likely a polygenetic effect the importance of which is still being determined in human research (46). The GABA system is obviously a highly attractive target for pharmacological agents, and several agonists/analogues are already in clinical use or development $(2,46,53)$. Research priorities include determining the effects of targeting different subunits of the receptor, and whether there are ways to reduce the concerns about tolerance and abuse relating to these agents (46). Besides its inherent role in anxiety, the GABA systems interacts not only with the glutamatergic systems, but also with serotonergic and opioid systems, which may account for some of the anxiolytic effects of agents targeting all 3 of these systems $(46,50)$.

Research on glutamate is another key focus for deepening our understanding of anxiety, and is revealing groundbreaking insights $(38,51)$. Glutamatergic neurons are widely distributed throughout the fear circuitry of the brain, and variability within this system is regarded as highly likely to contribute towards the development of anxiety disorders $(38,44)$. Glutamate is central to synaptic plasticity processes relevant to learning and memory, and to hypothalamic regulation of the acute stress response $(44,51)$. Through effects on ionotropic and metabotropic (Mglu) receptors, glutamate regulates multiple intracellular processes, and agents acting on the glutamatergic system, such as memantine, pregabalin and riluzole, have already been shown to be effective anxiolytics $(38,44)$. Novel Mglu receptor agonists have shown particular promise in preclinical studies and may have a similar role to benzos without tolerance and dependence risk, while Mglu antagonists and selective antagonists may 
Accepted Manuscript.

Book chapter (https://doi.org/10.1007/978-3-319-70554-5 2) published in "Advances in Psychiatry" (https://doi.org/10.1007/978-3-319-70554-5), Springer Nature, 07/07/2018.

also be valuable, in part because these receptors influence other anxiety-related systems (including the HPA axis, serotonergic system, and BDNF) $(38,51)$.

Conditioned fear acquisition has also been shown to depend on glutamate NMDA receptor mediated neuroplasticity in the amygdala, and manipulation of this receptor through the administration of the partial agonist $d$-cycloserine has been shown to augment exposure therapy in producing fear extinction in humans $(40,44$, 54). This exciting finding is an example of how pre-clinical neuroscience research has contributed directly to therapeutic approaches. Ongoing preclinical and clinical work on interventions which target the glutamatergic system, and the important interactions between GABA and glutamate are likely to result in improved understanding of and treatment for anxiety disorders (51).

\section{Neuropeptides}

A growing list of neuropeptides have a role in the etiology and possibly the management of anxiety. Neuropeptides are short chain fatty acids that act as neurotransmitters in various brain circuits (38), and those for which there is the most robust evidence of a role in anxiety include: substance $P$, neuropeptide $Y$, oxytocin, and galanin.

Substance $\mathbf{P}$ is the endogenous ligand of neurokinin 1 (NK1) receptors, which are distributed in the amygdala and hippocampus, and may be a mechanism for the production/expression of anxiety (45). Animal models involving receptor gene knockouts or administration of receptor antagonists have shown promising anxiolytic effects, with additional evidence that this ligand-receptor complex may have a beneficial influence on BDNF-dependent signaling and hippocampal neurogenesis similar to that induced by antidepressants (38). There have been mixed results in human trials, but a NK1 receptor antagonist may reduce symptoms in SAD, and further clinical development is underway $(38,45)$.

Neuropeptide $\mathrm{Y}$ (NPY) is widely expressed in the central nervous system including hippocampus and amygdala, suggesting broad involvement in physiological processes $(38,45)$. It interacts prominently with CRF/HPA-axis to regulate the stress response, and likely has a modulatory role in stress adaptation, especially to chronic stress, which is a recognized risk factor for anxiety $(38,45)$. In animal models, reduced NPY following acute stress is associated with increased anxiety, and pharmacological intervention studies support a role for NPY in moderating anxiety - with the injection of NPY reducing anxiety, while NPY gene knockout results in increased anxiety (45). The bulk of research on NPY at this stage is pre-clinical, but intranasal NPY has been trialed as a rapid acting anxiolytic (38).

Oxytocin is active in key nodes of the stress circuitry including the amygdala and hippocampus, whereby it regulates the stress response and stress-related behaviours (45). Its effects on the amygdala include inhibiting excitatory outflow to the brainstem, and modulating complex social behavior (38). In animal studies, administration of oxytocin appears to reduce anxiety levels, and oxytocin deficient rodents show increased anxiety, with heightened HPA-axis activity (45). Human research appears to support this, with polymorphisms of the oxytocin receptor gene resulting in increased vulnerability to stress (45). Human fMRI studies on the other hand, showed reduced amygdala activation in response to fear-inducing faces, and reduced amygdala- 
Accepted Manuscript.

Book chapter (https://doi.org/10.1007/978-3-319-70554-5 2) published in "Advances in Psychiatry" (https://doi.org/10.1007/978-3-319-70554-5), Springer Nature, 07/07/2018.

brainstem coupling, after intra-nasal oxytocin administration (38). Oxytocin analogies have been trialed in depression with promising results, suggesting further trials in anxiety disorders are warranted, with SAD thought to be the disorder most likely to benefit $(38,45)$.

Galanin targets receptors in the amygdala and hippocampus, and influences the serotonergic and noradrenergic systems, suggesting a high likelihood of involvement in stress and anxiety (45). Animal models show galanin antagonists to have both acute and chronic anxiolytic effects, in part due to a modulation of the usual inhibitory effects of galanin on the serotonergic system (38). The galanin system may also be upregulated in chronic stress, a finding which was reversed by antidepressants (45). Recent large scale genetic studies have identified an association between galanin gene polymorphisms, anxiety disorders and increased HPA axis activity in female patients, though the significance of this, and any role for galanin as a clinical treatment target in anxiety disorders remains to be clarified (45).

From this brief overview of several of the neuropeptides, there are indications that they may be amongst the various mechanisms for vulnerability to anxiety, and that they will inform new drug discovery, with multiple compounds targeting these systems currently being investigated $(38,45)$. It may also be that an improved understanding of the role of the various neuropeptides in the etiology of anxiety can contribute to the development of a biologically based diagnostic and classification system for anxiety disorders $(18,45)$.

\section{Genetics}

The final "micro" level to consider in attempting to understand the neurobiology of anxiety disorder is that of genetics. Anxiety disorders are strongly heritable, and there is growing direct evidence that genetic factors play a key role in vulnerability to and development of anxiety disorders $(46,55)$. This role for genetics is evident in the preceding discussion of the molecular sub-systems involved in anxiety, including the value of genetic manipulation studies (such as animal gene knockout approaches) in exploring these systems (56). Nevertheless, translating findings at the genetic level into clinical applications such as novel diagnostic and treatment strategies remains a challenge $(46,55)$. Genetic vulnerability for anxiety disorders likely stems from the influence of multiple genes, each with a small effect, as well as complex geneenvironment interactions and ongoing epigenetic processes $(35,46,55)$.

Still, multiple genes with relevance to anxiety disorders in humans have been identified including those coding for: COMT; cholecystokinin; 5HT1A and 5HT2A receptors, serotonin transporter $(5 \mathrm{HTT})$, monoamine oxidase $\mathrm{A}$, and BDNF - all of which may contribute towards the development of novel anxiolytic agents in the future $(43,46,55)$. Two genetics research approaches which will likely produce important findings over time include genome-wide association studies (GWAS) and endophenotypic studies. GWAS, which survey the whole genome as a broad approach to identifying abnormalities contributing towards anxiety disorders are currently underway, and while several associated genes have been identified, this research is at a very early stage in terms of its clinical utility (57). Endophenotypic studies, on the other hand, are intermediate studies which investigate the genetic component of 
Accepted Manuscript.

Book chapter (https://doi.org/10.1007/978-3-319-70554-5 2) published in "Advances in Psychiatry" (https://doi.org/10.1007/978-3-319-70554-5), Springer Nature, 07/07/2018.

common behavioural or neurobiological traits identified in those with anxiety, and may contribute to transdiagnostic understanding $(46,55,58)$.

On this background, a key strategy which will promote continued advancements in understanding the genetic basis of anxiety disorders, is the development of robust, bidirectional translational models whereby discoveries in both animals and humans can be developed and tested out using the full range of neuroscientific methodologies $(46,55,56)$.

Having briefly reviewed the important and interesting findings emerging from the neuroscience of anxiety disorders, it is clear that there is extensive overlap between the larger brain circuits and systems, and the distribution of the molecular pathways and genetics aspects just described, which may indicate they are amongst the proximal mechanisms whereby those larger systems mediate their effect on anxiety $(43,44,51)$. Secondly, it is obvious that there are extensive interconnections between the various molecular subsystems (50), indicating the complexity of the challenge of determining the neurobiology of anxiety, and thus the importance of further research in clarifying any clinical applications $(18,46,51)$.

Neuroscience research provides a valuable framework for understanding anxiety disorders in terms of pathogenesis, vulnerability and symptom production, as well as highlighting the mechanisms by which established treatments may have their effects, and helping with identification of possible new diagnostic and classification biomarkers and treatment targets. Nevertheless, clinical research is just as vital to assess how to make best use of existing treatments in the management of anxiety disorders in real world settings - the focus of the final section of this chapter.

\section{Section 3: Treating anxiety disorders - current practice and emerging approaches}

In the context of their epidemiology, the ongoing debates regarding their classification and conceptualization, and the promising but still incomplete neuroscience perspective, the practicing clinician must determine how best to manage anxiety disorders. Several recent international guidelines and related literature exist to guide treatment strategies, and highlight emerging approaches that are gaining ground $(2,52,59-61)$. This section is a practical introduction to this literature, and will aim to integrate information from the preceding sections in a unifying way, while pointing out where further research is needed.

\section{Considerations in the general approach to anxiety disorders}

Important general considerations for successfully managing anxiety disorders start with appropriate screening for these conditions, especially in high risk groups, establishing the presence of comorbid psychiatric and physical illness (which is highly likely), and determining the severity of symptoms and their functional impact on the individual. Once the correct diagnosis has been made, and the need for treatment established, the choice of particular treatments depends on research evidence, specific clinical characteristics (which may be differentially targeted by the various treatment options), comorbid illnesses and other medications being used (which may 
Accepted Manuscript.

Book chapter (https://doi.org/10.1007/978-3-319-70554-5 2) published in "Advances in Psychiatry" (https://doi.org/10.1007/978-3-319-70554-5), Springer Nature, 07/07/2018.

constrain the pharmacological options), as well as the preferences and past treatment experiences of the patient (including tolerability of medication), and finally, the local availability of the various possible interventions $(2,52)$

The clinician can then select from a range of psychological and pharmacological options in formulating an individualized treatment plan. Psychological treatments include supportive counseling, interpersonal therapy, exposure therapy, traditional cognitive behaviour therapy (CBT), psychodynamic therapy and newer transdiagnostic CBT and mindfulness-based approaches $(2,52,62,63)$. Evidence-based pharmacological options include several different categories of medication: SSRIs and SNRIs, other antidepressant drugs, benzodiazepines, alpha2delta ligands (specifically pregabalin), and other agents such as buspirone, antipsychotics and antihistamines, with several new agents in active development $(2,60,62)$. This broad range of treatments allows for considerable flexibility $(2,52,60,62)$.

While recommendations vary for individual disorders, an important initial decision is between psychological and pharmacological management. Research, including meta-analysis, suggests that patients often have a strong preference for psychological treatment, and that it is beneficial both acutely and for relapse prevention (2, 64-66). Psychological treatment likely achieves its effects via modification of the brain circuitry described in section 2, particularly via effects on the interaction between the PFC and the amygdala $(10,40,42)$. While the efficacy of psychological and pharmacological treatments for anxiety disorders have usually been regarded as broadly similar (2), a recent meta-analysis indicates that medications may be superior (62). Efficacious therapeutic modalities include mindfulness, CBT, exposure therapy, relaxation training, psychodynamic therapy and eye movement desensitization and reprocessing (62). CBT and exposure therapy are particularly widely practiced and show equivalent benefit across disorders, except for SAD where CBT appears superior (67). An often-stated advantage of psychological treatment over medication is that psychotherapy does not have side effects, though this claim has been refuted $(68,69)$. An important disadvantage compared with medication is reduced availability due to therapists needing special training and the reality of treatment waiting lists, given that between 8-20 hour-long treatment sessions may be required $(2,62)$.

The reality of psychotherapy side effects notwithstanding, medication side effects (including for antidepressants the FDA back box warning regarding increased suicidality), as well as drug interactions, discontinuation syndromes and, in some cases, addiction potential, are significant $(2,62,70)$. In addition, important concerns relate to the high placebo response when medication is used to treat anxiety, and further large-scale, pragmatic, industry-independent trials which control for this are needed to clarify the true picture (71). Nevertheless, the existing pharmacological options clearly target various components of the fear circuitry and molecular subsystems described above $(38,46)$, suggesting a strong theoretical basis for their use. The advantage of medications over psychological treatment, apart from greater efficacy (62), may be their ability to produce more rapid relief of symptoms, and that they require less clinician time (2). Furthermore, they may be the more obvious choice for initial treatment of severe symptoms and severe comorbid depression (2).

Depending on the response to either psychological or pharmacological 
Accepted Manuscript.

Book chapter (https://doi.org/10.1007/978-3-319-70554-5 2) published in "Advances in Psychiatry" (https://doi.org/10.1007/978-3-319-70554-5), Springer Nature, 07/07/2018.

treatment, clinician's may need to determine if combination treatment should be offered. This is an area of active research interest, and while it remains uncertain if a combined approach is superior in the long-term, there is some evidence that the addition of medication can enhance the efficacy of CBT in the short-term, which may be valuable $(2,72-74)$. A pragmatic and resource-conscious approach, given uncertainty in the literature about the comparative benefits of these treatment modalities alone or in combination, is the stepped-care approach advocated by the National Institute for Clinical Excellence (61). This proposes comprehensive screening and assessment, psychoeducation and active monitoring (step 1); followed if needed by low-intensity psychological interventions (including self-help; group support - step 2); progressing to high intensity psychological interventions (such as CBT) OR medication treatment (step 3); and finally, the combination of psychological and medication treatment, including inpatient treatment when needed (step 4).

Considering that anxiety disorders are frequently undiagnosed, and/or are inappropriately or under-treated, it is important to emphasizes again the heavy disease burden associated with these conditions $(1,4,12)$. Given the range of treatment options, it is usually possible to develop a care plan that addresses the needs of the individual. In support of this, the advances in neuroscience described earlier are contributing towards the identification and development of biomarkers (including neuroimaging and molecular features) which can predict response to specific treatments and thus guide treatment selection and sequencing $(75,76)$. In addition, further large prospective cohort studies, RCTs and meta-analyses of the medication and psychotherapy options will continue to refine treatment approaches $(1,2,62)$. Following from this, recommendations for the individual disorders will now be described.

\section{Treatment recommendations for specific disorders}

Generalised anxiety disorder: in line with the stepped-care approach, psychoeducation and psychological interventions such as CBT should be considered. Evidenced-based medication options include a range of antidepressants (SSRIs, SNRIs, TCAs, agomelatine and trazadone); pregabalin; benzodiazepines; buspirone; antipsychotics (notably quetiapine); and the antihistamine hydroxyzine (2). For most patients, an initial trial of an SSRI is recommended, and there is some evidence for the superiority of sertraline and fluoxetine $(61,77)$, though meta-analysis suggests that SNRIs may in fact be the most efficacious (62). Consistent with positive systematic reviews and meta-analysis, pregabalin is emerging as a valuable first-line agent, with the advantage of more rapid onset than antidepressants, and the ability to assist in relieving associated depressive symptoms when used as monotherapy $(53,78)$. While benzodiazepines can provide rapid relief in the short-term, including while initiating antidepressant agents, there are obvious concerns regarding tolerance and dependence, and long-term use should be avoided (61). For not-response to a firstline option, trials of alternatives from different classes and with different neurotransmitter receptor targets should be attempted, e.g. switching from an SSRI to an SNRI, TCA or pregabalin $(2,60)$. There is only limited evidence for dosage increase as a strategy, though higher doses of pregabalin may be the exception $(2,53)$. Combination treatment should be considered in resistant cases, aiming to extend the 
Accepted Manuscript.

Book chapter (https://doi.org/10.1007/978-3-319-70554-5 2) published in "Advances in Psychiatry" (https://doi.org/10.1007/978-3-319-70554-5), Springer Nature, 07/07/2018.

breadth of neurobiological systems targeted, e.g. combining an SSRI or SNRI with pregabalin or buspirone or $\mathrm{CBT}(52,60,72)$, and there is evidence that the addition of CBT may be particularly valuable (72). Further strategies, such as the addition of low dose antipsychotics or regular benzodiazepines, are also described, though given the disadvantages as well as inconsistencies in the literature, these should likely be regarded as a last resort $(2,52)$. Once a beneficial response has been achieved, there appears to be substantial ongoing benefit from staying on active treatment over the long-term $(2,52,60)$.

Panic disorder and agoraphobia: the involvement of the fear circuitry and fear conditioning processes in producing anticipatory anxiety and avoidance in panic disorder and agoraphobia $(10,17,40)$, indicates the value of CBT and exposure therapy, which modify these processes $(40,42)$. There is good evidence for the value of these psychological interventions, and they should be considered first-line, but they are not clearly superior to medication monotherapy $(2,52)$. It is important to note that while these two conditions frequently co-occur, the DSM 5 clearly recognizes their independence (7), though there is little known on the best treatment approach for agoraphobia in the absence of panic disorder (2). For first-line medication treatment, it is reasonable to consider similar antidepressants to those used for GAD, with the MAOI phenelzine, the RIMA moclobamide, and mirtazapine being additional options $(2,52,60)$. The literature is inconsistent on the relative advantages of the different antidepressants, and they are likely equivalent in terms of both efficacy and tolerability (2). As alternatives, there is some evidence for monotherapy with the anticonvulsants gabapentin and sodium valproate (2). Several widely-used agents, notably buspirone, bupropion and the beta-blocker propranolol, lack obvious efficacy and should not be utilized $(2,52)$. Benzodiazepines are effective, and may offer particular value in easing the heightened anxiety which can occur during initiation of antidepressants in those with panic disorder, but there is strong tolerance and dependence potential with longer-term use $(2,60)$. If there is inadequate response to initial treatment, higher dose monotherapy is worth considering $(2,60)$, as is switching between medication classes, and combination treatment with agents from different classes, though antipsychotics do not appear to add value for acute treatment $(2,52)$. Switching from medication treatment to psychological treatment is also evidencebased, and the combination of CBT and antidepressants also appears superior to either given alone for achieving an acute response, but there is no clear benefit of this combination for relapse prevention when compared to monotherapy $(2,52)$. An important new development is the effectiveness of augmenting exposure therapy with the administration of the glutamate receptor partial agonist $d$-cycloserine, which may hasten and increase the overall response to therapy - discussed in more detail below $(54,79)$. Finally, long-term treatment is beneficial, and though the optimal duration of treatment for relapse prevention is uncertain, durations of as long as 3 years have shown value $(2,60)$.

Specific phobia: this is the most common anxiety disorder and the one most comparable neurobiologically to fear-related responses in animals, highlighting the value of animal models $(10,17,40)$. Though this disorder has been under-researched 
Accepted Manuscript.

Book chapter (https://doi.org/10.1007/978-3-319-70554-5 2) published in "Advances in Psychiatry" (https://doi.org/10.1007/978-3-319-70554-5), Springer Nature, 07/07/2018.

in comparison to the others discussed here, there is clear benefit from multi-session, exposure-based psychological treatments $(2,80)$. In vivo exposure is regarded as most effective, but some interesting new work suggests the feasibility and value of computer-based virtual exposure - discussed in more detail below $(81,82)$. As for panic disorder, $d$-cycloserine augmentation of exposure therapy is an emerging strategy, though still largely in the research arena (54). The majority of patients respond to psychological approaches, and these should be first-line, but the addition of medication, particularly the SSRIs escitalopram and paroxetine is evidence based, especially for those who initially struggle to tolerate exposure (2). There is no clear benefit for the addition of benzodiazepines as adjuncts to exposure therapy itself, but there may be some value for intermittent dosing to allow patients to tolerate feared but unavoidable situations, such as medical procedures $(2,52)$.

Social anxiety disorder: there is the risk that SAD can be dismissed as mere "shyness" and not treated, an approach which can be avoided through careful screening (2). This can be a debilitating condition, including high comorbidity with depression and substance use disorder $(8,11)$, but it may respond well to treatment. Psychological intervention is recommended, and in contrast to specific phobia and panic disorder, CBT is regarded as superior to exposure therapy $(2,67,83)$, though there is emerging evidence for the augmentation of exposure with d-cycloserine (54). There is proven efficacy for a range of antidepressants, including most SSRIs, SNRIs, phenelzine and moclobemide, while the benefits of TCAs are unclear $(2,83)$. Alternatives include benzodiazepines, anticonvulsants (including gabapentin and pregabalin) and olanzapine, with higher dose pregabalin now regarded as a first-line option $(2,52,84$, 85). Importantly, neither buspirone or beta-blockers are effective for generalised SAD as monotherapy, though the latter may be beneficial for "performance anxiety" relating to specific scenarios (e.g. musicians, public speakers) (2). There is still no final consensus on the relative benefits of any particular intervention. In terms of medication, SSRIs and SNRIs may be the best choices (83), while some evidence indicates that the combination of CBT and the SSRI escitalopram is superior to CBT alone (74). A recent meta-analysis suggests, however, that individual CBT monotherapy is most effective (83). For initial non-response, higher dose antidepressant treatment is not evidence-based, but higher dose pregabalin may be advantageous $(2,84,85)$. Switching to an alternative agent from another class, as well as combination treatment are also recommended strategies, though the evidence of benefit is relatively weak (2). Longer-term treatment is indicated, as the proportion of patients responding to treatment increases steadily over time, with ongoing benefit from staying on active treatment for up to 6 months after response $(2,60)$.

\section{Pharmacological advances - further thoughts on alpha2delta ligands}

As already described, the alpa2delta ligands pregabalin and gabapentin are recognized treatments for a range of anxiety disorders, with especially pregabalin regarded as a first-line choice for $\operatorname{GAD}$ and $\operatorname{SAD}(2,53)$. While both these agents were originally developed as anticonvulsants (86), they are given special mention here as an example of the valuable influence of basic neuroscience, and data gathered in other research spheres on modern treatment approaches for anxiety disorders. 
Accepted Manuscript.

Book chapter (https://doi.org/10.1007/978-3-319-70554-5 2) published in "Advances in Psychiatry" (https://doi.org/10.1007/978-3-319-70554-5), Springer Nature, 07/07/2018.

Alpha2delta ligands target voltage-gated calcium channels, thereby modulating the release of neurotransmitters from nerve terminals, essentially acting as analogs of GABA, the main inhibitory neurotransmitter, and thereby reducing neurotransmission in excited neurons (86). Having been effectively used for epilepsy since 2004, it soon became clear that they had additional benefits, including for neuropathic pain and anxiolysis (86). Based on this, and the robust pre-clinical research indicating a central role for the GABA system in the neurobiology of fear and anxiety $(36,46)$, extensive further pre-clinical and clinical investigation of these agents has been undertaken with regards to their potential to augment GABAergic pathways in the fear circuits, and thereby treat anxiety disorders (53). Gabapentin has shown some value in panic disorder and social anxiety disorder, though admittedly as a second or third line agent only $(2,52)$. Pregabalin, on the other hand, has emerged as an evidence-based firstline monotherapy treatment for both $\operatorname{GAD}$ and $\operatorname{SAD}(52,53,78,84,85,87)$. In GAD, there is additional evidence for adjunctive benefit when added to SSRIs in those who have not responded to monotherapy, as well as a direct effect in improving comorbid depressive symptoms $(53,88)$, and in $S A D$, long-term pregabalin may reduce relapse rates (89).

In comparison to other first-line treatments, pregabalin appears to offer equivalent efficacy and a more rapid onset of action than the SSRIs (90), though it is not more efficacious than CBT in SAD (83). It does however offer a favourable side effect profile, and a much lower risk of tolerance and dependence than benzodiazepines $(53,78,87)$. While further pragmatic, head-to-head studies between pregabalin and other first-line medications are required to confirm comparable efficacy, and direct comparison trials of pregabalin and psychological treatments are a notable gap in the literature, this is an agent increasingly being used in the modern pharmacological management of anxiety disorders.

\section{Psychotherapy advances - focus on exposure augmentation and mindfulness}

Two relatively novel treatments which are gaining momentum in the psychological management of anxiety disorders include exposure augmentation strategies, and mindfulness-based interventions (MBIs).

Though still largely employed in the research setting, augmentation of exposure therapy with the glutamate NMDA receptor partial agonist $d$-cycloserine has already been mentioned as beneficial in the management of panic disorder, specific phobia and SAD (2). D-cycloserine administered just prior to exposure increases the likelihood of fear-extinction, resulting in a more rapid response to exposure therapy, though does not appear to increase the total degree of response when compared to a full course of standard therapy $(38,40)$. Theoretical justification for the use of $d$ cycloserine is based on the distribution of glutamatergic neurons throughout the fear circuitry, and the role of NMDA receptors in fear conditioning processes relying on synaptic plasticity as described previously $(38,44)$. This is a valuable example of how translational neurobiological research contributes towards successful clinical management. Importantly, while a recent meta-analysis confirmed the benefit of $d$ cycloserine for augmenting CBT-based exposure therapy for a range of anxiety disorders (panic, SAD and specific phobia) (54), a Cochrane review could not conclude in favour of $d$-cycloserine, though the authors commented that this was largely due 
Accepted Manuscript.

Book chapter (https://doi.org/10.1007/978-3-319-70554-5 2) published in "Advances in Psychiatry" (https://doi.org/10.1007/978-3-319-70554-5), Springer Nature, 07/07/2018.

to the poor quality of the evidence, and they recommended further large-scale studies (91). Apart from d-cycloserine, other agents have been trialed to augment exposure therapy, including cortisol, catecholamines, yohimbine and oxytocin, with partial research support for these approaches, though specific treatment strategies (dosages, timing of administration etc.) and overall recommendations remain to be determined (79).

Mindfulness, on the other hand, is a rapidly growing wave that is sweeping through both psychiatry and broader society. There is significant "hype" surrounding mindfulness-based treatment approaches, and while due caution is advised in assessing their value and potential role, as should be the case with any new therapeutic approach, there is growing evidence of substantial benefit for treating anxiety disorders $(92,93)$. Originating in eastern philosophical and spiritual practices based around meditation to develop attentional skills and awareness of present moment experience, mindfulness practices allow a shift towards equanimity, and a non-judgmental attitude $(94,95)$. In addition, there is a decentering from overidentification with arising thoughts and sensations, which has obvious application in relation to ruminative worry and physical symptoms of anxiety $(94,95)$. The modern mindfulness movement, in the form of Mindfulness Based Stress Reduction (MBSR) was initially focused on supporting those with chronic physical illness cope better with their symptoms (96). It has since gained ground as a component of various treatment approaches, most notably Mindfulness Based Cognitive Therapy (MBCT), Dialectical Behaviour Therapy (DBT), and Acceptance and Commitment Therapy (ACT), for a range of psychological and psychiatric conditions, including anxiety disorders (93, 94, 97, 98).

Clinical trials and systematic reviews show both an acute and sustained beneficial effect of MBCT, ACT and MBSR for a range of anxiety disorders including panic disorder, SAD and GAD (92-94, 99). In terms of possible mechanisms of benefit, there are sound theoretical justifications to indicate that enhancing mindfulness may augment exposure and facilitate fear extinction (95). While this still needs to be comprehensively tested, it is an intriguing possibility with special relevance to the anxiety disorders. These findings are promising, but it is important to note that MBIs have not consistently been shown to be superior to standard treatment $(62,94,100)$, and there are important methodological concerns relating to the research conducted so far, most notably around satisfactory control groups, to determine if it is mindfulness itself (rather than some confounding variable) which is responsible for the apparent benefit (94). Further research with larger study groups, active controls, and longer-term follow-up are needed to clarify the true value of MBIs in anxiety disorders, while neuroscience research continues to clarify the neural mechanisms involved (101). Pending this, mindfulness appears to represent a reasonable adjunctive or alternative treatment for specific patient sub-groups (102), or when first-line approaches have been unsuccessful, though it is likely to gain in prominence with time (92-94). 
Accepted Manuscript.

Book chapter (https://doi.org/10.1007/978-3-319-70554-5 2) published in "Advances in Psychiatry" (https://doi.org/10.1007/978-3-319-70554-5), Springer Nature, 07/07/2018.

\section{Conclusions - what's on the horizon?}

This chapter has highlighted the significant disease burden associated with anxiety disorders, discussed some of the issues relating to classification, and described the fascinating and rapidly advancing neurobiological understanding of these distressing conditions. Having subsequently reviewed standard treatment approaches, as well as recent pharmacological and psychotherapeutic advances, it remains to consider cutting-edge ideas that can carry the field forward in the technological age. While trans-disciplinary neuroscience is a prominent example of this, and will continue to add value $(10,17)$, direct patient interventions which make effective use of existing technology present a fascinating opportunity which is beginning to be realised.

The wide availability and advanced level of development of smartphones, the speed and ease of use of internet-based platforms, and the rapidly expanding world of virtual reality, present new heights from which to view the study and treatment of anxiety. For example, the limited availability of trained psychotherapists in any one location is a problem potentially remediated by online therapy (103). While difficulties in ensuring adequate exposure to a feared stimulus in real-world sessions can be resolved using the essentially limitless options and fine-grained level of control provided by virtual reality platforms $(81,82)$. Add in the constant presence of smartphones and other handheld interactive devices, and you have powerful tools for the collection of large volumes of individualized, health-related research data, as well as a convenient route for the direct and personalized delivery of therapeutic content anywhere, anytime $(103,104)$. Finally, considering that invasive treatment approaches (such as deep brain stimulation, vagal nerve stimulation and transcranial magnetic stimulation) which may directly target the brain circuits involved in anxiety, are already in development or early clinical trials, it is possible that important advances in the treatment of anxiety disorders are on the horizon $(40,105)$.

\section{References}

1. Kessler RC, Aguilar-Gaxiola S, Alonso J, Chatterji S, Lee S, Ormel J, et al. The global burden of mental disorders: an update from the WHO World Mental Health (WMH) surveys. Epidemiol Psichiatr Soc. 2009;18(1):23-33.

2. Baldwin DS, Anderson IM, Nutt DJ, Allgulander C, Bandelow B, den Boer JA, et al. Evidencebased pharmacological treatment of anxiety disorders, post-traumatic stress disorder and obsessivecompulsive disorder: a revision of the 2005 guidelines from the British Association for Psychopharmacology. J Psychopharmacol. 2014;28(5):403-39.

3. Baxter AJ, Patton G, Scott KM, Degenhardt L, Whiteford HA. Global epidemiology of mental disorders: what are we missing? PLoS One. 2013;8(6):e65514.

4. Steel Z, Marnane C, Iranpour C, Chey T, Jackson JW, Patel V, et al. The global prevalence of common mental disorders: a systematic review and meta-analysis 1980-2013. Int J Epidemiol. 2014;43(2):476-93.

5. Baxter AJ, Scott KM, Vos T, Whiteford HA. Global prevalence of anxiety disorders: a systematic review and meta-regression. Psychol Med. 2013;43(5):897-910.

6. de Jonge P, Roest AM, Lim CC, Florescu SE, Bromet EJ, Stein DJ, et al. Cross-national epidemiology of panic disorder and panic attacks in the world mental health surveys. Depress Anxiety. 2016;33(12):1155-77.

7. Diagnostic and statistical manual of mental disorders (5th ed.): American Psychiatric Association; 2013. 
Accepted Manuscript.

Book chapter (https://doi.org/10.1007/978-3-319-70554-5 2) published in "Advances in Psychiatry" (https://doi.org/10.1007/978-3-319-70554-5), Springer Nature, 07/07/2018.

8. Slade T, McEvoy PM, Chapman C, Grove R, Teesson M. Onset and temporal sequencing of lifetime anxiety, mood and substance use disorders in the general population. Epidemiol Psychiatr Sci. 2015;24(1):45-53.

9. Angst J, Gamma A, Baldwin DS, Ajdacic-Gross V, Rossler W. The generalized anxiety spectrum: prevalence, onset, course and outcome. European archives of psychiatry and clinical neuroscience. 2009;259(1):37-45.

10. Stein DJ. Advances in Understanding the Anxiety Disorders: The Cognitive-Affective Neuroscience of @False Alarms@. Annals of Clinical Psychiatry. 2006;18(3):10.

11. Hofmeijer-Sevink MK, Batelaan NM, van Megen HJ, Penninx BW, Cath DC, van den Hout MA, et al. Clinical relevance of comorbidity in anxiety disorders: a report from the Netherlands Study of Depression and Anxiety (NESDA). J Affect Disord. 2012;137(1-3):106-12.

12. Baxter AJ, Vos T, Scott KM, Ferrari AJ, Whiteford HA. The global burden of anxiety disorders in 2010. Psychol Med. 2014;44(11):2363-74.

13. Whiteford HA, Degenhardt L, Rehm J, Baxter AJ, Ferrari AJ, Erskine HE, et al. Global burden of disease attributable to mental and substance use disorders: findings from the Global Burden of Disease Study 2010. Lancet. 2013;382(9904):1575-86.

14. Walker ER, McGee RE, Druss BG. Mortality in mental disorders and global disease burden implications: a systematic review and meta-analysis. JAMA Psychiatry. 2015;72(4):334-41.

15. Meier SM, Mattheisen M, Mors O, Mortensen PB, Laursen TM, Penninx BW. Increased mortality among people with anxiety disorders: total population study. The British Journal of Psychiatry. 2016.

16. Tyrer P. Time to choose - DSM-5, ICD-11 or both? Archives of Psychiatry and Psychotherapy. 2014;3:4.

17. Williams LM, Goldstein-Piekarski AN, Chowdhry N, Grisanzio KA, Haug NA, Samara Z, et al. Developing a clinical translational neuroscience taxonomy for anxiety and mood disorder: protocol for the baseline-follow up Research domain criteria Anxiety and Depression ("RAD") project. BMC Psychiatry. 2016;16:68.

18. Insel TR. The NIMH Research Domain Criteria (RDoC) Project: precision medicine for psychiatry. Am J Psychiatry. 2014;171(4):395-7.

19. Francis A. Saving normal: An insider's revolt against out-of-control psychiatric diagnosis, DSM5, Big Pharma, and the medicalization of ordinary life. New York: William Morrow; 2013.

20. Zoellner LA, Rothbaum BO, Feeny NC. PTSD NOT AN ANXIETY DISORDER? DSM COMMITTEE PROPOSAL TURNS BACK THE HANDS OF TIME. Depression and Anxiety. 2011;28(10):853-6.

21. Pai A, Suris AM, North CS. Posttraumatic Stress Disorder in the DSM-5: Controversy, Change, and Conceptual Considerations. Behavioral sciences (Basel, Switzerland). 2017;7(1).

22. Stein DJ, Craske MA, Friedman MJ, Phillips KA. Anxiety disorders, obsessive-compulsive and related disorders, trauma- and stressor-related disorders, and dissociative disorders in DSM-5. Am J Psychiatry. 2014;171(6):611-3.

23. Katz C, Stein MB, J S. Anxiety Disorders in the DSM-5: New Rules on Diagnosis and Treatment Mood and Anxiety Disorders Rounds. 2013;2

(3):6.

24. Kendler KS, First MB. Alternative futures for the DSM revision process: iteration v. paradigm shift. Br J Psychiatry. 2010;197(4):263-5.

25. Surís A, Holliday R, North CS. The Evolution of the Classification of Psychiatric Disorders. Behavioral Sciences. 2016;6(1):5.

26. First MB. Paradigm shifts and the development of the diagnostic and statistical manual of mental disorders: past experiences and future aspirations. Canadian journal of psychiatry Revue canadienne de psychiatrie. 2010;55(11):692-700.

27. Kogan CS, Stein DJ, Maj M, First MB, Emmelkamp PM, Reed GM. The Classification of Anxiety and Fear-Related Disorders in the ICD-11. Depress Anxiety. 2016;33(12):1141-54.

28. Stein DJ, Kogan CS, Atmaca M, Fineberg NA, Fontenelle LF, Grant JE, et al. The classification of Obsessive-Compulsive and Related Disorders in the ICD-11. J Affect Disord. 2016;190:663-74.

29. Luciano M. The ICD-11 beta draft is available online. World Psychiatry. 2015;14(3):375-6.

30. Research Domain Criteria (RDoC): National Institute of Mental Health; 2017 [Available from: https://www.nimh.nih.gov/research-priorities/rdoc/index.shtml. 
Accepted Manuscript.

Book chapter (https://doi.org/10.1007/978-3-319-70554-5 2) published in "Advances in Psychiatry" (https://doi.org/10.1007/978-3-319-70554-5), Springer Nature, 07/07/2018.

31. Simpson HB. THE RDOC PROJECT: A NEW PARADIGM FOR INVESTIGATING THE PATHOPHYSIOLOGY OF ANXIETY. Depression and Anxiety. 2012;29(4):251-2.

32. Cryan JF, Sweeney FF. The age of anxiety: role of animal models of anxiolytic action in drug discovery. Br J Pharmacol. 2011;164(4):1129-61.

33. Fox AS, Kalin NH. A translational neuroscience approach to understanding the development of social anxiety disorder and its pathophysiology. Am J Psychiatry. 2014;171(11):1162-73.

34. Neurobiology of Mental Illness (4th Edition). 4th ed. New York: Oxford University Press; 2013. 35. Martin El, Ressler KJ, Binder E, Nemeroff CB. The Neurobiology of Anxiety Disorders: Brain Imaging, Genetics, and Psychoneuroendocrinology. The Psychiatric clinics of North America. 2009;32(3):549-75.

36. Bishop SJ. Neurocognitive mechanisms of anxiety: an integrative account. Trends Cogn Sci. 2007;11(7):307-16.

37. Brühl AB, Delsignore A, Komossa K, Weidt S. Neuroimaging in social anxiety disorder-a metaanalytic review resulting in a new neurofunctional model. Neurosci Biobehav Rev. 2014;47:260-80.

38. Mathew SJ, Price RB, Charney DS. Recent advances in the neurobiology of anxiety disorders: implications for novel therapeutics. Am J Med Genet C Semin Med Genet. 2008;148C(2):89-98.

39. Morrison FG, Ressler KJ. From the neurobiology of extinction to improved clinical treatments. Depress Anxiety. 2014;31(4):279-90.

40. Milad MR, Rosenbaum BL, Simon NM. Neuroscience of fear extinction: implications for assessment and treatment of fear-based and anxiety related disorders. Behav Res Ther. 2014;62:17-23.

41. Etkin A, Wager TD. Functional neuroimaging of anxiety: a meta-analysis of emotional processing in PTSD, social anxiety disorder, and specific phobia. Am J Psychiatry. 2007;164(10):147688.

42. Kindt M. A behavioural neuroscience perspective on the aetiology and treatment of anxiety disorders. Behav Res Ther. 2014;62:24-36.

43. Domschke K, Dannlowski U. Imaging genetics of anxiety disorders. Neuroimage. 2010;53(3):822-31.

44. Harvey BH, Shahid M. Metabotropic and ionotropic glutamate receptors as neurobiological targets in anxiety and stress-related disorders: focus on pharmacology and preclinical translational models. Pharmacol Biochem Behav. 2012;100(4):775-800.

45. Kormos V, Gaszner B. Role of neuropeptides in anxiety, stress, and depression: from animals to humans. Neuropeptides. 2013;47(6):401-19.

46. Olivier JD, Vinkers $\mathrm{CH}$, Olivier $\mathrm{B}$. The role of the serotonergic and GABA system in translational approaches in drug discovery for anxiety disorders. Front Pharmacol. 2013;4:74.

47. Gordon JA, Hen R. The serotonergic system and anxiety. Neuromolecular medicine. 2004;5(1):27-40.

48. Ressler KJ, Nemeroff CB. Role of serotonergic and noradrenergic systems in the pathophysiology of depression and anxiety disorders. Depression and Anxiety. 2000;12(S1):2-19.

49. Stein DJ, Ahokas AA, de Bodinat C. Efficacy of agomelatine in generalized anxiety disorder: a randomized, double-blind, placebo-controlled study. Journal of clinical psychopharmacology. 2008;28(5):561-6.

50. Colasanti A, Rabiner EA, Lingford-Hughes A, Nutt DJ. Opioids and anxiety. J Psychopharmacol. 2011;25(11):1415-33.

51. Nicoletti F, Bockaert J, Collingridge GL, Conn PJ, Ferraguti F, Schoepp DD, et al. Metabotropic glutamate receptors: from the workbench to the bedside. Neuropharmacology. 2011;60(7-8):1017-41. 52. Katzman MA, Bleau P, Blier P, Chokka P, Kjernisted K, Van Ameringen M, et al. Canadian clinical practice guidelines for the management of anxiety, posttraumatic stress and obsessive-compulsive disorders. BMC Psychiatry. 2014;14 Suppl 1:S1.

53. Baldwin DS, den Boer JA, Lyndon G, Emir B, Schweizer E, Haswell H. Efficacy and safety of pregabalin in generalised anxiety disorder: A critical review of the literature. J Psychopharmacol. 2015;29(10):1047-60.

54. Rodrigues H, Figueira I, Lopes A, Gonçalves R, Mendlowicz MV, Coutinho ES, et al. Does Dcycloserine enhance exposure therapy for anxiety disorders in humans? A meta-analysis. PLoS One. 2014;9(7):e93519. 
Accepted Manuscript.

Book chapter (https://doi.org/10.1007/978-3-319-70554-5 2) published in "Advances in Psychiatry" (https://doi.org/10.1007/978-3-319-70554-5), Springer Nature, 07/07/2018.

55. Domschke K, Maron E. Genetic factors in anxiety disorders. Modern trends in pharmacopsychiatry. 2013;29:24-46.

56. Jacobson LH, Cryan JF. Genetic approaches to modeling anxiety in animals. Current topics in behavioral neurosciences. 2010;2:161-201.

57. Otowa T, Hek K, Lee M, Byrne EM, Mirza SS, Nivard MG, et al. Meta-analysis of genome-wide association studies of anxiety disorders. Mol Psychiatry. 2016;21(10):1391-9.

58. Spielberg JM, Miller GA, Warren SL, Sutton BP, Banich M, Heller W. TRANSDIAGNOSTIC DIMENSIONS OF ANXIETY AND DEPRESSION MODERATE MOTIVATION-RELATED BRAIN NETWORKS DURING GOAL MAINTENANCE. Depression and anxiety. 2014;31(10):805-13.

59. Bandelow B, Sher L, Bunevicius R, Hollander E, Kasper S, Zohar J, et al. Guidelines for the pharmacological treatment of anxiety disorders, obsessive-compulsive disorder and posttraumatic stress disorder in primary care. Int J Psychiatry Clin Pract. 2012;16(2):77-84.

60. Taylor D, Paton C, Kapur S. The Maudsley Prescribing Guidelines in Psychiatry (11th ed.): WileyBlackwell; 2012.

61. Excellence NIfHaC. Generalised anxiety disorder and panic disorder in adults: management. NICE guideline (CG113) [Internet]. 2011.

62. Bandelow B, Reitt M, Röver C, Michaelis S, Görlich Y, Wedekind D. Efficacy of treatments for anxiety disorders: a meta-analysis. Int Clin Psychopharmacol. 2015;30(4):183-92.

63. Norton PJ, Barrera TL. Transdiagnostic versus Diagnosis-Specific CBT for Anxiety Disorders: A Preliminary Randomized Controlled Non-inferiority Trial. Depression and anxiety. 2012;29(10):874-82.

64. DiMauro J, Domingues J, Fernandez G, Tolin DF. Long-term effectiveness of CBT for anxiety disorders in an adult outpatient clinic sample: a follow-up study. Behav Res Ther. 2013;51(2):82-6.

65. Meuldijk D, Carlier IV, van Vliet IM, van Veen T, Wolterbeek R, van Hemert AM, et al. The clinical effectiveness of concise cognitive behavioral therapy with or without pharmacotherapy for depressive and anxiety disorders; a pragmatic randomized controlled equivalence trial in clinical practice. Contemp Clin Trials. 2016;47:131-8.

66. Hofmann SG, Smits JAJ. COGNITIVE-BEHAVIORAL THERAPY FOR ADULT ANXIETY DISORDERS: A META-ANALYSIS OF RANDOMIZED PLACEBO-CONTROLLED TRIALS. The Journal of clinical psychiatry. 2008;69(4):621-32.

67. Ougrin D. Efficacy of exposure versus cognitive therapy in anxiety disorders: systematic review and meta-analysis. BMC Psychiatry. 2011;11(1):200.

68. Linden M, Schermuly-Haupt M-L. Definition, assessment and rate of psychotherapy side effects. World Psychiatry. 2014;13(3):306-9.

69. Berk M, Parker G. The Elephant on the Couch: Side-Effects of Psychotherapy. Australian \& New Zealand Journal of Psychiatry. 2009;43(9):787-94.

70. McCain JA. Antidepressants and Suicide in Adolescents and Adults: A Public Health Experiment with Unintended Consequences? Pharmacy and Therapeutics. 2009;34(7):355-78.

71. Stein DJ, Baldwin DS, Dolberg OT, Despiegel N, Bandelow B. Which factors predict placebo response in anxiety disorders and major depression? An analysis of placebo-controlled studies of escitalopram. The Journal of clinical psychiatry. 2006;67(11):1741-6.

72. Campbell-Sills L, Roy-Byrne PP, Craske MG, Bystritsky A, Sullivan G, Stein MB. Improving outcomes for patients with medication-resistant anxiety: effects of collaborative care with cognitive behavioral therapy. Depress Anxiety. 2016;33(12):1099-106.

73. Cuijpers P, Sijbrandij M, Koole SL, Andersson G, Beekman AT, Reynolds CF. Adding psychotherapy to antidepressant medication in depression and anxiety disorders: a meta-analysis. World Psychiatry. 2014;13(1):56-67.

74. Gingnell M, Frick A, Engman J, Alaie I, Björkstrand J, Faria V, et al. Combining escitalopram and cognitive-behavioural therapy for social anxiety disorder: randomised controlled fMRI trial. $\mathrm{Br} J$ Psychiatry. 2016;209(3):229-35.

75. Shin LM, Davis FC, Vanelzakker MB, Dahlgren MK, Dubois SJ. Neuroimaging predictors of treatment response in anxiety disorders. Biol Mood Anxiety Disord. 2013;3(1):15.

76. Lueken U, Zierhut KC, Hahn T, Straube B, Kircher T, Reif A, et al. Neurobiological markers predicting treatment response in anxiety disorders: A systematic review and implications for clinical application. Neurosci Biobehav Rev. 2016;66:143-62. 
Accepted Manuscript.

Book chapter (https://doi.org/10.1007/978-3-319-70554-5 2) published in "Advances in Psychiatry" (https://doi.org/10.1007/978-3-319-70554-5), Springer Nature, 07/07/2018.

77. Baldwin D, Woods R, Lawson R, Taylor D. Efficacy of drug treatments for generalised anxiety disorder: systematic review and meta-analysis. BMJ. 2011;342.

78. Generoso MB, Trevizol AP, Kasper S, Cho HJ, Cordeiro Q, Shiozawa P. Pregabalin for generalized anxiety disorder: an updated systematic review and meta-analysis. Int Clin Psychopharmacol. 2017;32(1):49-55.

79. Hofmann SG, Mundy EA, Curtiss J. Neuroenhancement of Exposure Therapy in Anxiety Disorders. AIMS Neurosci. 2015;2(3):123-38.

80. Choy Y, Fyer AJ, Lipsitz JD. Treatment of specific phobia in adults. Clin Psychol Rev. 2007;27(3):266-86.

81. Bouchard S, Dumoulin S, Robillard G, Guitard T, Klinger E, Forget $H$, et al. Virtual reality compared with in vivo exposure in the treatment of social anxiety disorder: a three-arm randomised controlled trial. The British Journal of Psychiatry [Internet]. 2016 10/03/2017:[8 p.].

82. Valmaggia LR, Latif L, Kempton MJ, Rus-Calafell M. Virtual reality in the psychological treatment for mental health problems: An systematic review of recent evidence. Psychiatry Res. 2016;236:189-95.

83. Mayo-Wilson E, Dias S, Mavranezouli I, Kew K, Clark DM, Ades AE, et al. Psychological and pharmacological interventions for social anxiety disorder in adults: a systematic review and network meta-analysis. Lancet Psychiatry. 2014;1(5):368-76.

84. Kawalec $P$, Cierniak A, Pilc A, Nowak G. Pregabalin for the treatment of social anxiety disorder. Expert opinion on investigational drugs. 2015;24(4):585-94.

85. Feltner DE, Liu-Dumaw M, Schweizer E, Bielski R. Efficacy of pregabalin in generalized social anxiety disorder: results of a double-blind, placebo-controlled, fixed-dose study. Int Clin Psychopharmacol. 2011;26(4):213-20.

86. Taylor CP, Angelotti T, Fauman E. Pharmacology and mechanism of action of pregabalin: the calcium channel alpha2-delta (alpha2-delta) subunit as a target for antiepileptic drug discovery. Epilepsy Res. 2007;73(2):137-50.

87. Frampton JE. Pregabalin: a review of its use in adults with generalized anxiety disorder. CNS Drugs. 2014;28(9):835-54.

88. Rickels K, Shiovitz TM, Ramey TS, Weaver JJ, Knapp LE, Miceli JJ. Adjunctive therapy with pregabalin in generalized anxiety disorder patients with partial response to SSRI or SNRI treatment. Int Clin Psychopharmacol. 2012;27(3):142-50.

89. Greist JH, Liu-Dumaw M, Schweizer E, Feltner D. Efficacy of pregabalin in preventing relapse in patients with generalized social anxiety disorder: results of a double-blind, placebo-controlled 26-week study. Int Clin Psychopharmacol. 2011;26(5):243-51.

90. Cvjetkovic-Bosnjak M, Soldatovic-Stajic B, Babovic SS, Boskovic K, Jovicevic M. Pregabalin versus sertraline in generalized anxiety disorder. An open label study. European review for medical and pharmacological sciences. 2015;19(11):2120-4.

91. Ori R, Amos T, Bergman H, Soares-Weiser K, Ipser JC, Stein DJ. Augmentation of cognitive and behavioural therapies (CBT) with d-cycloserine for anxiety and related disorders. Cochrane Database Syst Rev. 2015(5):CD007803.

92. Kim YW, Lee SH, Choi TK, Suh SY, Kim B, Kim CM, et al. Effectiveness of mindfulness-based cognitive therapy as an adjuvant to pharmacotherapy in patients with panic disorder or generalized anxiety disorder. Depress Anxiety. 2009;26(7):601-6.

93. Gotink RA, Chu P, Busschbach JJ, Benson H, Fricchione GL, Hunink MG. Standardised mindfulness-based interventions in healthcare: an overview of systematic reviews and meta-analyses of RCTs. PLoS One. 2015;10(4):e0124344.

94. Norton AR, Abbott MJ, Norberg MM, Hunt C. A Systematic Review of Mindfulness and Acceptance-Based Treatments for Social Anxiety Disorder. Journal of Clinical Psychology. 2015;71(4):283-301.

95. Treanor M. The potential impact of mindfulness on exposure and extinction learning in anxiety disorders. Clin Psychol Rev. 2011;31(4):617-25.

96. Kabat-Zinn J. Full catastrophe living: Using the wisdom of your body and mind to face stress, pain, and illness. New York: Dell Publishing; 1990. 
Accepted Manuscript.

Book chapter (https://doi.org/10.1007/978-3-319-70554-5 2) published in "Advances in Psychiatry" (https://doi.org/10.1007/978-3-319-70554-5), Springer Nature, 07/07/2018.

97. Williams JMG, Russell I, Russell D. Mindfulness-Based Cognitive Therapy: Further Issues in Current Evidence and Future Research. Journal of Consulting and Clinical Psychology. 2008;76(3):5249.

98. Chapman AL. Dialectical Behavior Therapy: Current Indications and Unique Elements. Psychiatry (Edgmont). 2006;3(9):62-8.

99. Vøllestad J, Sivertsen B, Nielsen GH. Mindfulness-based stress reduction for patients with anxiety disorders: evaluation in a randomized controlled trial. Behav Res Ther. 2011;49(4):281-8.

100. Wong SY, Yip BH, Mak WW, Mercer S, Cheung EY, Ling CY, et al. Mindfulness-based cognitive therapy v. group psychoeducation for people with generalised anxiety disorder: randomised controlled trial. Br J Psychiatry. 2016;209(1):68-75.

101. Holzel BK, Hoge EA, Greve DN, Gard T, Creswell JD, Brown KW, et al. Neural mechanisms of symptom improvements in generalized anxiety disorder following mindfulness training. Neurolmage Clinical. 2013;2:448-58.

102. Arch JJ, Ayers CR. Which treatment worked better for whom? Moderators of group cognitive behavioral therapy versus adapted mindfulness based stress reduction for anxiety disorders. Behav Res Ther. 2013;51(8):434-42.

103. Dagöö J, Asplund RP, Bsenko HA, Hjerling S, Holmberg A, Westh S, et al. Cognitive behavior therapy versus interpersonal psychotherapy for social anxiety disorder delivered via smartphone and computer: a randomized controlled trial. J Anxiety Disord. 2014;28(4):410-7.

104. Marzano L, Bardill A, Fields B, Herd K, Veale D, Grey N, et al. The application of mHealth to mental health: opportunities and challenges. The Lancet Psychiatry.2(10):942-8.

105. Marin MF, Camprodon JA, Dougherty DD, Milad MR. Device-based brain stimulation to augment fear extinction: implications for PTSD treatment and beyond. Depress Anxiety. 2014;31(4):269-78. 